\title{
TRANSFORMATIONAL LEADERSHIP, GENDER AND PERFORMANCE: EVIDENCE FROM A DEVELOPING ECONOMY
}

\author{
Badiul Alam, Dhaka Commerce College, Bangladesh \\ Lokman Mia, Griffith University, Australia
}

\begin{abstract}
This study examines the relationship between senior managers' (SM's) transformational leadership style and department managers' (manager's) performance taking into account the impact of -managers' gender on the relationship. A self-administered questionnaire was used to collect the data. Completed and usable questionnaires were received from 103 managers in charge of departments (accounting and finance, human resource management, sales and marketing, and customer services.

The transformational leadership style (TLS) and performance were measured using instruments adapted from previous studies. The results revealed that superiors' TLS was positively associated with the performance of subordinate managers in charge of the above mentioned departments. The results a/so revealed that the managers' gender did not impact the relationship between the TLS and performance. Implications of the results are discussed later in the paper.
\end{abstract}

Keywords: leadership, relationship, senior managers, TLS

\section{INTRODUCTION}

Prior researchers have argued that superiors' (senior managers') TLS can motivate subordinates to improve their performance which, in turn, results in improved organisational performance (Patiar and Mia, 2009; Boerner et at., 2007; Hinkin and Tracey, 1994). The relevant literature (Boerner et at., 2007; Hinkin and Tracey, 1994) suggests that practising TLS is an effective management tool to deal with the increasingly competitive business environment. Managers with TLS can act as role models and inspire employees to put the good of the organization above self-interest (Patiar and Mia, 2009, Bass, 1985). Our literature search revealed that though a number of studies (e.g., Patiar and Mia., 2009; Boerner et at., 2007; Hinkin and Tracey, 1994; Boerner et at., 2007; Hinkin and Tracey) have investigated the infiuence of TLS on outcome variables such as performance in Western countries having developed economies. Proponents of contingency theory (e.g., Chenhall, 2003) suggest that the impact of factors such as TSL on an outcome variable depends on organizational context. This study investigated the relationship between TLS and managerial performance taking into account the potential impact of gender in the context of Bangladesh.

Gender mix in workforce is continually increasing around the world and senior managers need to understand the consequences of this trend (Leong \& Seralica, 2001). Therefore, the question of whether a person's gender affects any aspect of his or her performance at work deserves inquiry. This study focused on finding if managers' gender affects the relationship between the TLS and performance.

\section{THEORY AND HYPOTHESIS}

2.1 The relationship between transformational leadership style and performance

Bass (1985) argues that superiors' having TLS are able to reveal a high level of trust in, communicate a sense of purpose to, and can inspire motivation among, subordinates by communicating important purpose in simple ways, promote intelligence, stimulation and problem solving behavior, and promote individuality. Previous researchers report that superiors with TLS are particularly able to motivate employees who, in turn, make better decisions '!nd achieve improved performance. For instance, Xenikou and Simosi (2006) report that the TLS positively influences subordinates' performance by promoting subordinates' high level of motivation (see also Boerner et at., 2007). Wilkins et at. (2007) and Zelie et at. (1994) argue that motivated employees are more likely to deliver better performance. Patiar and Mia (2009) argue that a reason for the success of superiors with TLS in motivating employees to perform better is that they (superiors) empowers subordinates to make decisions without having first to seek the superior's approval. 
In summary, previous research on the TLS indicates that superiors' adoption of TLS creates a work environment conducive to sharing the organizational vision, inspiring and intellectually stimulating and instilling higher order ideals and values among subordinates (Bass and Avolio, 1997; Burns, 1978). The research also indicates that employees working under a superior with TLS are empowered and experience high job satisfaction and organizational commitment, which results improved performance (Arnold et al., 2001). Hypothesis one formally presents the discussions.

Hypothesis 1. There is a positive relationship between a superiors' transformational leadership style and subordinates' performance.

\subsection{The impact of gender.}

In today's workplace, number of female employees is increasing in most countries around the world. So, management ought to understand the consequences of the increasing gender mix (Leong \& Seralica, 2001).

However, though many studies conducted to assess the potential impact of employees' gender on the relationship between a predictor variable and employee performance, the results are inconclusive. For instance, Campbell (2011) reports that, in some instances, a legitimate correlation between gender and an outcome variable such as performance or job satisfaction may be found within a specific workplace or organization under certain conditions and may not be found in other conditions.

This finding is consistent with other relevant research (Winant, 2006; Molnar, 2005); Gianakos, 2002; Ryan \& Deci, 2000). Campbell (2011), concludes that overall within the United States, gender is not a reliable indicator or predictor of workers' degree of satisfaction with a job.

Consistent with the findings of previous research on this issue, we also predict that there will be no difference in performance of female and male employees in an organization in a developing economy like that in Bangladesh. Hypothesis 2 formally presents this argument.

Hypothesis 2. Employees' gender has no impact on their performance.

\section{RESEARCH METHOD}

3.1. The Sample. The data were collected from department managers in charge of accounting and finance (AF), personnel/human resource management (HRM), sales and marketing (SM), and customer service (CS) departments in 103 medium to large (annual sales revenue of BDT. 900 millions to 1200 millions) financial services, garments, and nongovernment organizations in Bangladesh.

3.2. The Data Collection.

Initially, the GMs (general manager, HRM) of 150 medium to large organisations were contacted in writing explaining the purpose of the study and assuring complete confidentiality of the information to be collected.

Each GM was assured of (i) using the information only for the study, (ii) providing the overall aggregate results of the study, and if desired (iii) explaining the results in a seminar for management of the participating companies. A sample of the questions used for the data collection was provided and explained to the GMs.

Out of the 150 GMs contacted, 58 agreed to let her/his company participate in the study and provided contact of 232 department managers. We wrote a personal letter to each of the 232 managers (a) explaining the purpose of the study, (b) assuring anonymity of all participants and. attached with a copy of the finalised questionnaire and a prepaid self-addressed envelope for returning the completed questionnaire direct to the author. Out of the 232 nominated department managers, 103 (53 male and 50 female) fully completed and returned the questionnaire.

Thus, the final sample was 103 yielding a response rate of over $44.4 \%$. On average the participants 
had worked for their firms for 6 years ranging from 4 to 11 years, were $25 \%$ in charge of $A F, 27 \%$ in charge of HRM, $26 \%$ in charge of SM and $22 \%$ in charge of CS departments 


\subsection{Measurement of Variables}

3.3.1. Transformational leadership style

To measure TSL, this study followed Patiar (2005) in using Bass and Avolio's (1997) revised Multifactor Leadership Questionnaire (MLQ-Form 5X) comprising 20 items related to superiors TLS. Ali 20 transformational leadership items were measured using a 5- point Likert scale where managers were asked to indicate how often the 20 TLS behaviors represent their general manager.

Here, 1 indicated "almost never" and 5 indicated "almost always". Consistent with the approach of Avolio et'al. (1999), Banerji and J<rishnan (2000), Chen (2004), the mean of 20 items was taken to compute the global score representing the managers' perceptions of their GM's TLS.

The Cronbach alpha 0.89 for the overall sample achieved was in line with that between .87 and .96 reported by other researchers (e.g., Arnold et al., 2001) and was satisfactory as it is above 0.70 , recommended by Nunnally (1978). The descriptive statistics for TSL.[\{for the overall sample was 3.77 with 0.68 (std. dev.) and 1.00-500 (min- max actual range)\}, \{for the Female was 3.35 with 1.08 (std. dev.) and $1.00-500$ (min - max actual range)\}and for the Male managers was 3.33 with 0.96 (std. dev.) and 1.00-500 (min-max actual.range))] respectively.

\subsubsection{Managerial petformance}

Since the present study was concerned with managerial performance, we followed Ferris (1977) in defining the construct as the extent of managers' achievement of target (planned) performance. Ferris's definition of performance is especially suitable for defining managerial performance where jobs are complex and tess predictable/routine (see Mia, 1984).

The managers were asked to indicate using a 5-point Likert scale the extent to which they achieved their overall planned performance during last year. On the scale, 1 indicated "very low" and 5 indicated "very high".

The descriptive statistics for performance [\{for the overall sample was 3.21 with 0.97 (std. dev.) and 1.00-500 (min- max actual range)\}, \{for the Female was 3.23 with 0.78 (std. dev.) and 1.00-500 (min- max actual range)\}and for the Male managers was 3.19 with 0.81 (std. dev.) and 1.00-500 (min-max actual range)\}] respectively.

\subsubsection{Gender was measured as $1=$ Female; $0=$ Male.}

\section{RESULTS}

\subsection{Test of the Hypothesis}

Hypothesis $H_{1}$ predicts a positive relationship between department managers' performance and the general managers' TSL.

it was tested by regressing performance against TSL. The model explained $6.9 \%$ of the variance (R. Square $=6.90 \%$; Adjusted R Square $=4.50 \% ; F\left(I_{1021}=5.91 ; P=0.05\right)$ in managerial performance .

Also, the results revealed that the relationship between TSL and managers' performance was positive and significant $(($ the regression coefficient ()$=0.186, \mathrm{~T}$ value $=1.921, p<0.05))$, therefore the hypothesis was supported.

Hypothesis $\mathrm{H}_{2}$ predicts that managers' gender has no impact on the TSL - performance relationship. it was tested by sub-dividing the overall sample into Female and Male managers and then performance for each group was separately regressed against TSL for the group.

The results for both of the groups were nolsignificant, therefore supporting the hypotheses that managers' gender does not influence the TSL - performance relationship.

\section{DiSCUSSION, LIMITATION AND CONCLUSIONS}

As hypothesis $\mathrm{H}_{1}$ was supported, the fundamental argument in the study that superiors' is a powerful factor that can influence employee performance. We argue that superiors' TLS is an effective management tool for motivating managers to try their best to improve their performance which, in turn, 


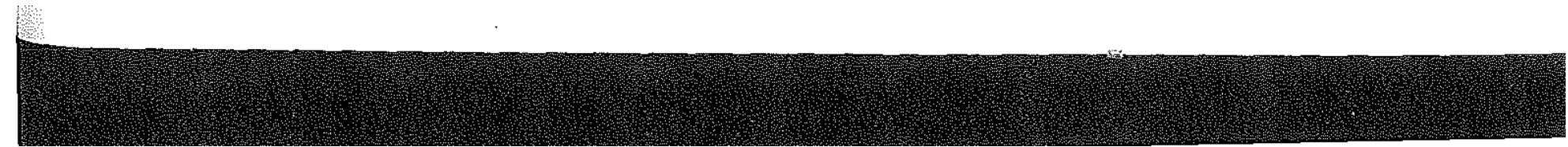


may improve organizational performance. The study also confirms that employee gender is not a reliable factor for predicting performance in a developing economy. This study confirms the results reported in prior studies (see Campbell, 2011).

The following limitations to this study deserve to be mentioned here. First, since the GMs of the initially selected organisations nominated the department managers to participate in the study, there could be a systematic bias in the sample.

Although we did not find any significant difference between the participating and the non-participating firms in terms of size, it is possible that managers in high performing firms completed our questionnaire.

Therefore, a generalization of the results requires caution. Second, the sample is based on department managers of the medium to large firms operating only in Bangladesh. Therefore, caution is needed in generalizing the findings to firms in other countries and to other managers. Future research to generalize the results: (i) to the next level of managers and (ii) to firms operating in other countries will be useful.

A practical implication of the results is that the top management in firms may consider encouraging senior managers to adopt TLS in dealing with their subordinate managers. This attempt may be supplemented by arranging suitable training for the senior managers to practice TLS.

A theoretical implication of the results is that the study confirms the usefulness of TLS as an important factor in improving employee performance even in a developing economy.

\section{REFERENCES:}

Arnold, K., Barling, J., l<elloway, 1<., (2001). Transformational leadership or the iron cage: which predicts trust, commitment and team efficacy? Leadership and Organizational Development Journal22 (7/8), 315-320.

Avolio, B., Howell, J., Sosik, J., (1999). A funny thing happened on the way to the bottom line: humour as a moderator of leadership style effects. Academy of Management Journal42 (2), 219-227.

Banerji, P., Krishnan, V., (2000). Ethical preferences of transformational leaders: an empirical investigation. Leadership and Organization Development Journal 21 (8), 405-413.

Bass, B., Avolio, B., (1997). Full Range of Leadership Development: Manual for the Multifactor Leadership Questionnaire. Mind Garden, Redwood City, CA.

Bass, B., (1985). Leadership and Performance Beyond Expectations. Free Press, New York.

Bass, B., Avolio, B., (1994). Improving Organisational Effectiveness Through Trans- formational Leadership. Sage Publication, Thousand Oaks, CA.

Bass, B., Avolio, B., (1997). Full Range of Leadership Development: Manual for the Multifactor Leadership Questionnaire. Mind Garden, Redwood City, CA.

Boerner, S., Eisenbeiss, S., Griesser, D., (2007). Followers behavior and organizational performance: the impact of transformational leaders. Journal of Leadership and Organizational Studies 13 (3), 15-26.

Burns, J., (1978). Leadership. Harper and Row, New York.

Campbell, D.G. (2011). Reconciling Conflicting Theories and Findings, International Journal of Applied Management and Technology, 10 (1), 1-15. 
Chen (2004), Examining the effects of organization culture and leadership behavior on organizational commitment, job satisfaction and job performance at small and middle-sized firms of Taiwan. Journal of American Academy of Business 5 (1/2), 432--438.

Chenhall, R. H. (2007). Theorizing Contingencies in Management Control Systems Research. In C. S. Chapman, A. G. Hopwood \& M. Shields, D. (Eds.), Handbooks of Management Accounting Research (Vol. 1, pp. 163-205): Elsevier.

Chenhall, R. $\dot{H}$. (2003). Management control systems design within its organizational context: findings from contingency-based research and directions for the future. Accounting, Organizations and Society, 28(2-3), 127-168.

Ferris, 1<. R. (1977). A test of the expectancy theory of motivation in an accounting environment, The Accounting Review, LII, 3, 605-615.

Gianakos, I. (2002, December). Issues of anger in the workplace: Do gender and gender roles matter? Career Development Quarterly, 51, 155-172

Hinkin, T., Tracey, J., (1994). Transformational leadership in the hospitality industry.Hospitality Research Journal18 (1), 49-61.

Leong, F. T., \& Seralica, F. (2001). Cross cultural perspective on Super's career development theory: Career maturity and cultural accommodation. In F. T. Leong, \& A. Barak (Eds.), Contemporary models in vocational psychology (pp. 167167-206). Mahwah, NJ:Erlbaum.

Mia, L. (1984). Participation in the budgetary process, task difficulty, locus of control, and and managerial performance, PhD dissertation, University of Queensland, Australia.

Molnar, S. (2005). Races, types and ethnic groups (4th ed.). Upper Saddle River, NJ: Prentice-Hall.

Nunnally, J., (1978). Psychometric Theory. McGraw-Hill, New York.

Patiar, A. (2005). Managers'perception of market competition, transformational leadership, use of MAS information and performance: a cross-cultural study in hotels. Doctor of Philosophy Thesis, Griffith University, Brisbane, Australia.

Patiar and Mia, (2009). Transformational leadership style, market competition and departmental performance: Evidence from luxury hotels in Australia, International Journal of Hospitality Management28(2009)254-262

Ryan, R. M., \& Deci, E. L. (2000, January). Self-determination theory and the facilitation of intrinsic motivation, social development, and well-being. American Psychologist, 55, 68 - 78.

Tracey, J., Hinkin, R., (1996). How transformational leaders lead in the hospitality industry. International Journal of Hospitality Management 15 (2), 165-176.

Wilkins, H., Meriless, B., Herington, C., (2007). Towards an understanding of total service quality in hotels. International Journal of Hospitality Management 26 (4), 840-853.

Winant, H. (2006). Race and racism: Toward a global future. Ethnic \& Racial Studies, The International Journal of Applied Management and Technology (IJAMT), 29, 986-1003.

Xenikou, A., Simosi, M., (2006). Organizational culture and transformational leader- ship as predictors of business unit performance. Journal of Managerial Psycho!- ogy 21 (6), 566-579.

Zelie, S., Sparrow, J., Woodfield, A., Kilmartin, T., (1994). The tyrannical chef: a barrier to TQM. International Journal of Hospitality Management 16 (1/2), 42--45.

Zwingman-Bagley, C., (1999). Transformational management style positively affects financial outcomes. Nursing Administration Quarterly 23 (4), 29-34. 




\section{AUTHORS PROFILE:}

Mr. Badiul Alam MBA, M.Com; is currently Associate Professor at Dhaka Commerce College, Dhaka, Bangladesh. Mr. Alam has published in International Journal of Business Research.

Dr. Lol<man Mia earned his PhD at University of Queensland, Australia 1n 1985. Currently he is Profesor of Accounting at Griffith University, Queensland, Australia. Dr. Mia published in Decision Sciences; Accounting, Organization and Society; Accounting and Business Research; Management Accounting Research; Accounting, Auditing and Accountability Journal; British Accounting Review; Financial Accountability and Management; International Journal Journal of Hospitality Management, Journal of Hospitality and Tourism Research. 